\title{
Looking for Peekaboo
}

\author{
Claiborne Rice \\ University of Louisiana
}

In the context of a preliminary investigation of peekaboo play in a local day care, this essay examines the particulars of one child's actions as she attempts to engage another child in peekaboo. Four elements of the child's performance contribute to its evaluation as peekaboo: the stylized motions of looking and eye-covering, the intent to make and keep eye contact with the play partner, the rhythmic timing of covering-uncovering motions, and the opportunistic nature of the attempt to play. Considering peekaboo as a folk illusion puts these kinds of early performances in the context of a developmental trajectory that spans the entire childhood.

This is a preliminary report on fieldwork in progress on Peekaboo. I became interested in peekaboo while studying the genre of folk illusions with Brandon Barker (Barker and Rice 2019). Peekaboo is interesting as a form because it is widespread and well-known, it appears to have all of the qualities of a folk illusion, and it is played by kids and the people around them from early infancy until well into the pre-school years. This latter quality is especially attractive because it appears to offer an opportunity to study the emergence of children's performative folkloric competence (McDowell 1977, $187 ; 2007-08,43)$. As with any other folkloristic form, observing the emergence of folk illusion performance in context can help us understand the nature of performance and of the purposes the performance of folk illusions may serve in the life of the individual and community.

Curiously, despite the ubiquity of peekaboo-like routines around the world, the form has been almost completely overlooked by folklorists. Simon Bronner mentions it in passing as a precursor to Hide and Seek $(1998,173 ; 2011,210)$. Kate Schramm, in her perceptive essay "Nascent Folklore" (2011), offers the only sustained folkloristic examination of peekaboo. While inviting folklorists to explore "infant interaction in an ethnographic context," she acknowledges challenges that inhere in studying folkloric 
forms in the "prelinguistic, pre-genre, pre-self arena of infant behavior" (7). Folklorists should not be distracted by interpreting children's activities simply as precursors of adult social competencies and should remain aware that children's forms are activated rather than transmitted, so that mutation and variation mark the creative expression of attempted forms (McDowell 1999, 62). Perhaps most importantly in the ethnographic context, pre-linguistic infants cannot report on their intentions, motivations, or goals. Schramm thus constructs a framework for interpreting infant behaviors in a folkloristic context. Her study of peekaboo illustrates how intention can be inferred by the researcher on the basis of certain behaviors of the child's: her sustained gaze, her creative permutations on a theme, and her signals of emotion like laughter and smiling (20).

Schramm's approach reads the child's play for traces of intention, as if intention may or may not be present and the observer's job is to witness it when it appears. There is a different way, however, to track the emergence of intention in the child's activity. Henry Glassie has said about performance that it "is an existential proposition." By this he means that it "establishes people as intelligent, sentient beings who receive and process and compose, and as beings who occupy and act upon the real world with all of its pain and wonder" (Glassie 2001, 45). From this perspective, as soon as we identify the play activity as a performance, then we have already identified the childish performer as an intentional agent, however small. Rather than scrutinizing behavior for traces of intention, we are instead asking what counts as performance.

If we consider the possibility that peekaboo is a folk illusion, then pre-linguistic peekaboo play is not necessarily also pre-genre. ${ }^{1}$ Folk illusions as a genre evince intentionality. Mature performers shape their materials under guidance from audience expectations to achieve various goals that performers target in advance. In our definition of folk illusions, we reference intention explicitly; they are "a traditionalized 
form including verbal and kinesthetic actions performed in order to effect an intended perceptual illusion for one or more participants" (Barker and Rice, 4). The director wishes to share an experience with the actor. Rather than telling the actor about their own experience, as we would for example in relating a personal story, the director instructs or shows the actor what to do, then waits for a reaction from the actor that is interpreted as evidence that the experience has happened. The fun of experiencing an illusion motivates kids to share their experience with others. Performances might be initiated by statements like "wanna see something cool?" or "I bet you can't pat your head and rub your tummy at the same time." Directors attempt to show or describe appropriate movements so that actors accomplish the illusions. Sometimes it takes more than one try to get a successful result. After the surprise or laughter subsides there might be some conversation about where the director learned the illusion or why it works. All of these performance elements imply intentionality. In addition, of course, intention becomes evident whenever we ask people about why they play folk illusions.

The age bands at which folk illusions tend to be played present an opportunity to examine how intention gets distributed throughout the forms as they are constituted and performed by youths of different ages and abilities (Table 1). Youths in their middle school years are the typical performers, but younger children are not left out. Certain forms are suited to the body awareness and socialization abilities of preschool kids. Most noticeably with younger children, older children or adults are the instigators of the fun. Some people remember an uncle or sibling showing them an illusion, but other illusions, like Got Your Nose (Barker and Rice, E1), do not come up as something people remember having been sprung on them as young kids. I have not yet met someone who remembers what it felt like to have their nose stolen and returned. So apparently it is possible to create an intended illusion for a person even if you yourself do not remember experiencing the illusion. 
Table 1: Age Ranges of Folk Illusions (Barker and Rice, 169)

\begin{tabular}{|l|l|l|}
\hline Ages & Typical Forms & Additional Characteristics \\
\hline Young child (2-5 yrs) & $\begin{array}{l}\text { Got Your Nose, Kiss Your } \\
\text { Elbow, Separating Thumb }\end{array}$ & $\begin{array}{l}\text { Adult or older child is } \\
\text { instigator; illusions target } \\
\text { immature body perception }\end{array}$ \\
\hline $\begin{array}{l}\text { Childhood through } \\
\text { adolescence (8-18) }\end{array}$ & $\begin{array}{l}\text { Pat and Rub, the Chills, } \\
\text { Floating Arms, Crossed } \\
\text { Hands, Light as a Feather }\end{array}$ & $\begin{array}{l}\text { Simpler forms earlier; } \\
\text { socially more complex } \\
\text { forms later }\end{array}$ \\
\hline Adulthood (18-80) & $\begin{array}{l}\text { Floating Arms, Arms or } \\
\text { Legs through the Floor }\end{array}$ & $\begin{array}{l}\text { Illusions played as pranks, } \\
\text { while stoned or high, or for } \\
\text { nostalgia }\end{array}$ \\
\hline
\end{tabular}

Peekaboo as a form seems to have all the necessary elements of a folk illusion. In Chapter 7 of Folk Illusions we present a morphology of peekaboo as it is often played when the child is very young (three to eight months) and the adult is the initiator (the agent, in our terms).

Peekaboo Morphology (Barker and Rice, 181)

a. Agent highlights performance space and time with eye contact / alert call

b. Agent initiates hiding activity

c. Priming period

d. Agent reappears / release call

e. Eye contact is re-established

f. Agent and Patient respond to each other

g. Optional re-initiation of hiding activity 
The time span between the breaking and re-establishment of eye contact, steps (b) and (e), is when the intended illusion would be taking place. But what is the intended illusion?

When I ask adults what they think the baby is experiencing during peekaboo, the most frequent statement is that the parent "disappears" for the baby. Some people offer a folk psychological explanation that the baby lacks "object permanence" - the baby thinks the parent is gone when the parent is hidden from sight, then suddenly reappears (Barker and Rice, 182). Adults think this is evidently an illusion on the child's part because of course the parents know they have not actually disappeared. As the children grow a bit older, though, between five to thirteen months, they begin gradually to demonstrate some agency in the context of peekaboo, able to key peekaboo play themselves with alert calls or by hiding their eyes, or grabbing the rag off mama's face, for example, as if to uncover her. One person I spoke to, Janna Haller, had a child who had matured enough that she could instigate peekaboo herself-she could perform some of the actions of the agent, in folk illusion terms (Barker and Rice, 182-84). Janna thus had a slightly different take on her child's experience. For her, the child thought that she was making herself disappear. The context of peekaboo play creates an environment where the child can be recognized as being an intentional agent, creating a desired effect for her, or for her mother.

We see a similar situation in Schramm's description of her daughter's peekaboo play. Schramm acknowledges that the play is a form that has been rehearsed many times within the family (19). Thus Schramm knows that when her daughter walks through the play area and disappears down a hallway, the child is keying a round of peekaboo:

I ask her where she is going (in high-pitched play tones) even as she disappears out of sight around a doorway. Then come the cue words of our game, which we 
have played numerous times before: "Where's [Name]?" The sing-song chant is repeated at a higher pitch. As the repetition of the cue comes to a close, the child runs out from the doorway with a huge smile on her face, looking for my face.

Schramm's report of the event artfully elides her own role in delivering the alert call for their game. "Then come the cue words...." The form itself seems to have supplied the cue words, almost as if they have dropped dramatically out of the ether to affirm the child's intention. Though the pre-linguistic child initiates the play by disappearing down the hall, Schramm conspires with her child to establish the play frame formally. In terms of our morphology, the agent role in the form has been split between the two participants. The child takes step (b) first, then Schramm takes step (a) in response to her daughter's adoption of the agency afforded her by the form. Schramm recognizes in her discussion of the event that parent and child have worked together to bring the play frame into being, and that it is within the frame that the child can manipulate expectations, control the length of the priming period, and experience the delight and surprise of reappearance (20). Viewing peekaboo as a folk illusion helps us understand how agency is distributed among different participants in a particular performance and how adults construct the imagined mental state of their little co-conspirators.

Because the possibilities afforded by studying peekaboo are so rich for understanding nascent folkloric performance, I began visiting a daycare at my church in Lafayette, Louisiana. The Little Lambs Mother's Day Out Program is housed in the Saint Barnabas Episcopal Church building on Camelia Boulevard, a recently widened road running between 50- to 60-year-old subdivisions. Saint Barnabas was founded in 1966 by the Diocese of Western Louisiana as a suburban option to the older and larger downtown church. The parish erected a multi-use building in the early 1970s that I have heard accurately described as a large brown Pizza Hut. A sacristy was built ten years 
later, and the local Episcopal School expanded their middle school program into the back of the original building. After the school moved into its own new building in 2011, the school rooms sat empty during the week. The day care program now occupies that space. The program is not intended to serve the congregation primarily but as a ministry to the local community. The day care is the brainchild of Kelly Labry, a lifelong parishioner of Saint Barnabas, who realized when her first child was born that a part time day care would be a great service to people like her who needed a break sometimes but did not need full time day care. Mother's Day Out, as they refer to themselves informally, is open from 9-1 Tuesday through Thursday, with a few kids coming in on Friday as needed.

My initial goal was to observe peekaboo being played by different age groups, starting as young as possible. The psychologists Anne Fernald and Daniela O'Neill reported in 1993 that adults were playing versions of peekaboo with infants as young as three months old (270). I expected I would see the staff playing peekaboo with children or the children playing some form of hiding games amongst themselves. Mother's Day Out's youngest class is 12-18 months, though, so I selected them to start with. I began visiting in August of 2019 as a preliminary step toward exploring the possibility of a long term study.

All of the classes have a schedule posted by the door of their room, and the 12-18 month class is no exception. The teachers, Sharona and Sabrina, keep everyone moving smoothly through the schedule as the day progresses. They accept arrivals after 9 a.m. with free play in the room, then get a snack after everyone is there. After that they play either inside or outside, depending on weather. Some days a part of free play is taken up with "Movement," which consists of going down to a different room and playing with large, soft balls and pool noodles with scarves tucked into the ends. Music plays fairly loudly and the staff encourages the older kids to use a variety of rhythm 
instruments like maracas or tambourines as they dance to the music. Our younger class, however, is content to play with the toys and explore the space.

After several days of observation I found myself focusing on the 10:30-11:30 a.m. time slot. After coming in from free play or Movement at 10:30, the class has lunch and lies down for naps, which begin around 11:30. Getting the whole class of eight lively kids through lunch and into naps is no easy task. As Anna Beresin illustrates in Recess Battles, transitions are tough on teachers and kids alike (23). Twelve months is about when most kids start walking. When the class started for the fall, three of the kids could walk, but by early October six of the eight could do it. All of the kids are mobile enough, however, to find their way around the $18 \times 18$ room in a hurry.

In order to manage everyone, the two teachers conduct a beautiful, intricate ballet of movements and tasks. As Sharona tells me, "you have to figure out how each child is and arrange for that. Some will sleep longer so you put them down first. Some will take other kids' food, so you have to feed them separately." The two teachers work together to get each kid's food out, get them fed and laid down on their nap-mats with their particular sleep aids. One child goes in a crib, two go down early, this one has to have a warm bottle, another must have a cloth over his head. All while this is going on, one of the teachers is making art with the kids. The room is equipped with a semicircular table sporting small booster seats around the outer curve. A teacher-usually Sabrina but they trade tasks sometimes - can sit at the inner hemisphere of the table and supervise the kids as they eat, spooning some applesauce into one mouth, handing a carrot stick to another child. As the kids eat, the teacher maneuvers one kid onto her lap or into the nearest seat on her left, where she can paint the kid's hand or foot and use it to make one or more imprints on a sheet of paper. Each kid gets painted, imprinted, and cleaned up during lunch. Then, usually while the kids are sleeping, the teachers add lines or glue other things to the paper to make a simple but often clever piece of art. The 
figure depicted on the page goes along with the school's "letter of the day." So for example they might make a handprint turkey for $\mathrm{T}$ day or a pink handprint elephant for E day. At the end of the month each child has a personal portfolio of art they have made, marked with a name and date to confirm it.

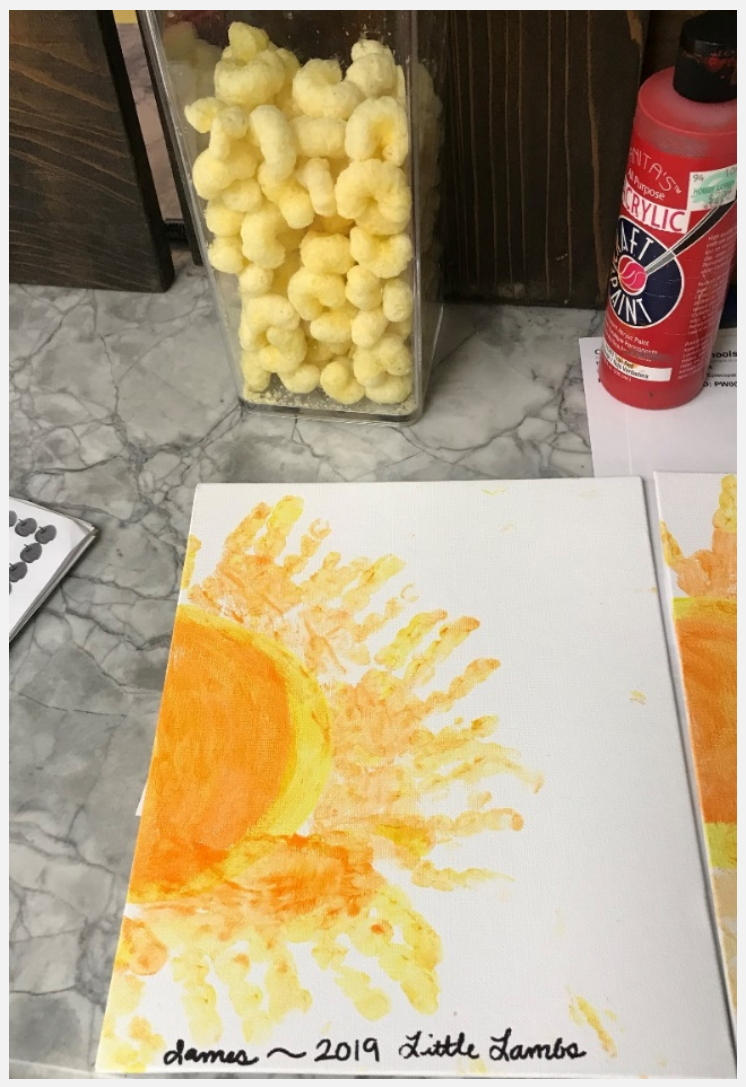

Hand Crafts and Snacks at Little Lambs Mother's Day Out Program

I watched over a month and saw no hint of peekaboo. Sabrina, who had graduated college in spring of 2017 and was taking classes for a nursing degree, said that she did not really play games with the kids. She liked to clap and sing with them instead. She thought the kids reacted well to music when they were crying. Sharona had graduated the year before with a degree in childhood education and was happy to be working with the younger group. She taught them some sign-language signs, such as those for drinking and eating, to help her communicate with them. When I asked if she played any games with the kids, she mentioned that if they were crying or in an angry 
mood, she might play peekaboo or patty cake. Changing diapers would be a likely occasion for peekaboo, she said, but I did not observe any performances. When I asked what she thought the kids enjoyed about peekaboo, she said that they enjoyed "seeing different things each time. When they cover their eyes it's dark. When they uncover it's light again and they see something different." Based on my observations, both teachers primarily used singing, humming, music, and rhythm to engage the children who were grumpy or crying. Except in the middle of nap time, the room was filled with noise and constant motion. The teachers also confirmed my observation that none of the children had any verbal words yet.

On October 3, 2019, I arrived around 10:00 during play time. They had not gone outside that day because they were making special art projects for Muffins with Mom day the next week. Each child was making a large sun with a footprint aurora and a caption reading MOM - You are my sunshine. "The mothers will love them!" Sabrina told me, when they come to have muffins at lunch the next Wednesday.

Sharona reported that the kids had started to fight over toys the day before so they had hidden the toy cupboard behind a towel. I did not see the kids express any interest in looking for toys, as they had a few larger play stations out in the room, a table, a Playskool farm gate they could walk through if they chose to, and three of those wooden boxes with the doodads you can move around on colorful wires, sometimes called bead mazes or activity cubes.

I took my usual place in a low chair so I could observe everyone. I had decided for this first semester of visits that I wanted to cause as little disruption to the classroom and its routines as I could. Adopting the role of an observer (Fine 1999, 128), I did not interact directly with the children unless they approached or involved me first, which they occasionally did. I would play with them or share their toys if they came over to 
where I sat, and I would return their smiles or waves if they smiled or waved first. As much as possible, though, I let the day go by as it normally would.

As I watched the kids who were not eating mill about on the floor, I noticed that dark haired, 15-month-old E- might be playing at hiding. At one point she was down on her hands and knees, moving toward the farm gate. She put her head through the gate and looked around until she saw me looking at her. Then she pulled her head back and looked at me from the other side of the gate. After a moment she put her head through again and looked at me, then looked away at something else and crawled through the gate. "Not quite a routine?" I wrote in my notes.

Later she stood on one side of a large activity cube and smiled at no one in particular. Then she put her head down and walked to the other side, then somewhat dramatically put her head up again. She looked around, and this time she caught my eye. She smiled, and I smiled back to let her know I had seen her. Then she walked back to the starting spot and repeated the looking and smiling. After she saw me looking back at her, she turned her attention to another toy and a different activity. I have to say I was a little disappointed -- "like just the verge of routine" I wrote.

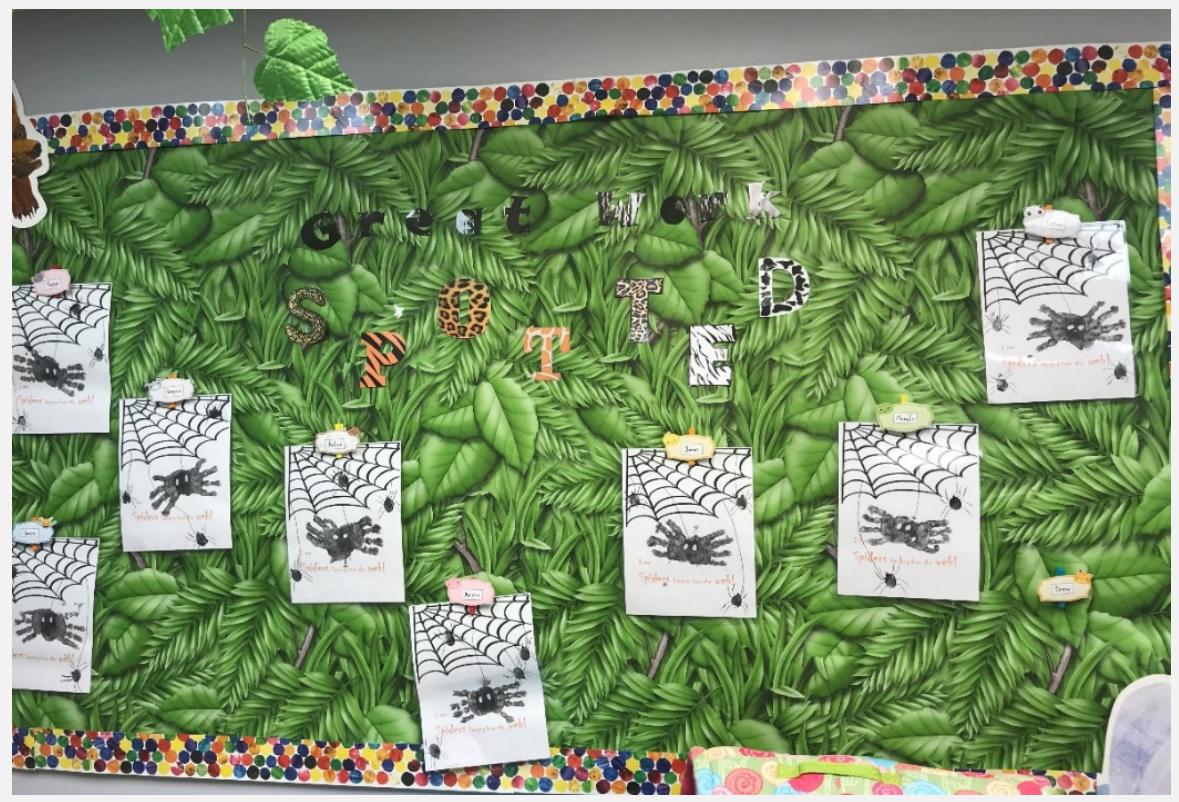

Completed Artwork Displayed on the Class Bulletin Board 
Later, after E- had eaten and made her art, it was her turn to be put down for her nap. When I began visiting, E- would cry herself to sleep every day, but she had eventually given that up and become a peaceful napper. Now she could start her naps with the main body of kids, neither early nor late. On this day Sharona set her nap mat down next to one of the boys, an early napper who took a bottle with him to sleep. He was on his side with his back to me, so I could not tell if he was asleep yet or not-he would usually nod off while sucking his bottle, so the motions I could see from behind his head did not give me any clues about his eyes. E- was sitting on her mat, so Sharona asked her to lie down. She did so, positioning herself on her left side facing me, looking at the child next to her. Sharona was sitting on the floor, rocking one of the other kids. She reached over and flipped E-'s cover over her, and as it covered her it also fell across her face. E- clasped the cover and slowly removed it from her face. She peeked across at the boy, then lowered the cover in front of her face again. After a beat she raised it up quickly and looked at him again. Maybe she didn't get a return look from him, because she next looked up and met my eyes. At once she covered and uncovered again in rhythm, this time seeking my eyes immediately. After a beat she covered up again. Before she could uncover again, Sharona addressed a loud "Lay Down" to another child. This might have distracted her, because she rolled over to look the other way at Sharona.

I excitedly marked a star in my notes to indicate this as a performance of peekaboo. My immediate judgment was that it was an intentional, opportunistic attempt to initiate peekaboo play. Now, looking back to the situation and the research context more broadly, I want to ask, what led me to categorize this third event as peekaboo while the other two only reached toward it? There are two elements that seem comparatively insufficient in the first two events to make the identification and two elements in the third event that stand out as important. One insufficient element is the 
stylized or formal nature of the movements before and after E- looked around. In most peekaboo play the motions take on an exaggerated, stylized, or dramatic characteristic that seems parallel to the exaggerated intonations of the alert and release calls. The motions accomplish a step in the form, and performers seem intent on making the motions in such a way as to call attention to them as part of a form rather than simply an everyday action. When E- stuck her head through the farm gate she did it as if she were crawling normally through the gate, and likewise when she backed out again. The motions lacked stylization. Moving to stand beside the activity box, however, had a clearly stylized nature. She seemed to measure her steps, then pause and hold herself upright, then raise her head boldly to look around. Though she took her position on either side of the activity box, it was not nearly large enough to conceal her, nor did she engage with respect to the box as if it were hiding her. It is not absolutely necessary for peekaboo that a child have something to hide her or conceal her eyes. I have seen more than one example of a kid "hiding in plain sight" by simply closing her eyes and turning her face away from the adult. But E-'s motions with respect to the box lacked clear orientation to a particular person with whom she might be trying to engage. She might have been conducting some other ritual to which I had no privileged access, but I could not tell.

The second element present that nonetheless seemed insufficient to make the two early events count as peekaboo was the attempt to make eye contact. In the usual interpersonal peekaboo form as described by our morphology, eye contact is the crucial event that shapes the nature of the other steps. ${ }^{2}$ That E- looked around and in fact did catch my eye at the farm gate and the activity box is at least part of what nominated the performances as peekaboo. But the quality of the eye contact is best described as looking around to see if someone had seen her. Once eye contact was made, she seemed 
satisfied to turn attention to something else. Even though the motion was repeated, the eye contact itself did not seem to be the goal of the movements.

In the third event, however, E - was looking at the boy across from her before her nap mat cover concealed her eyes. Eye contact is the first element for getting peekaboo started. When she uncovered her eyes, she was still looking directly at him. It seemed evident to me that she expected him to be as surprised by the sudden interruption of their gaze as she was. Because I was sitting behind the boy, my eyes were not too terribly far away from her line of sight. When she saw that I was looking at her, she slowly covered her eyes with the nap mat cover again. She waited a moment, then uncovered swiftly and was looking directly at me again. Her quick, controlled movement of the cover as if to surprise me had the dramatic quality I would expect, especially in contrast to the hasty throwing off of the cover that I could easily imagine in its place. So the gaze quality and stylization of movements that seemed insufficient in the first two events looked more like peekaboo in the third.

Alongside those two qualities were two additional, recognizable elements of peekaboo. The first was the rhythmic timing of the covering and uncovering. In all of the peekaboo I have watched, there is a clearly detectable element of dramatic timing or rhythm that develops among both adult and kid performers. The psychologist Jerome Bruner thought that the timing of the constituent parts of peekaboo was its most intriguing feature (Fernald and O'Neill 278). In folk illusion terms, the time that elapses while the eyes or face is covered is what we call the priming period. It is an emergent element of folk illusion structure determined largely by the adaptations the body must make to the odd conditions that the folk illusion performance usually foists upon the actor (Barker and Rice, 188). Some relevant conditions for E- might include the dim lighting of the room at the time, the distance of the boy's or my eyes from hers, and perhaps some awareness of how long it takes for someone to realize that eye contact has 
been broken. As Schramm also noticed in her description, the agent of peekaboo gets to manipulate expectations by controlling the timing element (20).

The other element of peekaboo evident in E-'s performance was the opportunism, a frequent element of adult descriptions of how peekaboo play works in both the psychological literature and among my interviewees. Psychologists describe how the sudden breaking of eye contact might happen, for example, when a shirt is pulled over a baby's head, and the parent will use the occasion to instigate a round of peekaboo (Bruner and Sherwood, 279; Fernald and O'Neill, 270). This opportunism sanctions play at unexpected moments, and allows for substitutions in what psychologists Nancy Ratner and Jerome Bruner first called the "semantic elements" of the form (392). The way the eyes are covered can vary, for example, from using a wash cloth or piece of clothing, to moving a child or adult body part to break eye contact. Adults I have spoken with also emphasized the flexible, opportunistic element of peekaboo. Janna Haller demonstrated how she would hold both her daughter's feet with one hand while changing her diaper, and raise the feet until the baby's face was obscured (Barker and Rice, 183).

The opportunism of peekaboo performances strikes me as an important creative element of the form. "Creativity," Henry Glassie once noted, "can be imagined as a combination of two processes. One is the mental process by which form is designed. The second is the bodily process of putting form into the world, adjusting it to have positive impact." A proverb, for example, is usually repeated verbatim, but "there is creativity in situating the proverb in the world in the right way, locating it in the flux of the instant so that it has consequence, function." At the other extreme from the proverb is the epic, where creativity far surpasses memorization (48). E- was presented with a sudden opportunity to play, and she grasped it immediately, manipulating the elements of her world to highlight the elements of the imagined form. If the child across 
from her wasn't going to respond, she sought out someone who would. Taken altogether, and in contrast to the earlier two events, the four characteristics of E-'s naptime performance worked together to compel me to label it as peekaboo.

The contrast of this episode with Schramm's description is also instructive. Schramm, with her daughter and husband, had built a community in which peekaboo was a shared form. Her description documents features of the household environment and the community that allowed her daughter to productively initiate a round of peekaboo that, in its opportunism and completion, allowed her daughter to be recognized as an intentional, creative agent. E-, on the other hand, was confronted with the same type of opportunity to initiate a form of play with which she seemed familiar, but discovered her environment and community, at that time at least, declined to join in her creativity and confirm her intentionality. Nonetheless, we are able to view E-'s performance as an attempt to transfer the familiar form into a new environment. Unfortunately, my research visits were interrupted by the restrictions put in place due to the COVID-19 pandemic before I could do more to follow up on peekaboo in the Mother's Day Out context. But E-'s performance demonstrated that in tracking the distribution of peekaboo play forms among the network of local communities, we may be able to learn more about how nascent forms of folklore play enrich communities in which we grow and live.

Claiborne Rice, associate professor of English at the University of Louisiana at Lafayette, has published articles on cognitive linguistics and poetics, and is currently investigating dialect diversity within Cajun English. His work on folk illusions, with Brandon Barker, is the first study of the traditions of childhood illusion play. 


\section{References Cited}

Barker, K. Brandon, and Claiborne Rice. 2019. Folk Illusions: Children, Folklore, and Sciences of Perception. Bloomington: Indiana University Press.

Beresin, Anna R. 2010. Recess Battles: Playing, Fighting, and Storytelling. Jackson: University Press of Mississippi.

Bronner, Simon. 2011. Explaining Traditions: Folk Behavior in Modern Culture. Lexington: University Press of Kentucky.

Bronner, Simon. 1998. Following Tradition. Logan, Utah: Utah State University Press. https://doi.org/10.2307/j.ctt46nqtf.8.

Bruner, Jerome, and V. Sherwood. 1976. "Peekaboo and the Learning of Rule Structure." In Play: Its Role in Development and Evolution, edited by Jerome Bruner, Alison Jolly, and Kathy Sylva, 277-85. New York: Basic Books.

Brunvand, Jan Harold. 1998. The Study of American Folklore: An Introduction. New York: Norton.

Fernald, Anne, and Daniela K. O’Neill. 1993. “Peekaboo across Cultures: How Mothers and Infants Play with Voices, Faces, and Expectations." In Parent-Child Play: Descriptions and Implications, edited by Kevin MacDonald, 259-85. Albany: SUNY Press.

Fine, Gary Alan. 1999. "Methodological Problems of Collecting Folklore from Children." In Children's Folklore: A Sourcebook, edited by Brian Sutton-Smith, Jay Mechling, Thomas W. Johnson, and Felicia R. McMahon, 121-40. Logan, Utah: Utah State University Press. https://doi.org/10.2307/j.ctt46nskz.13.

Glassie, Henry. 2001. "Performance Theory and the Documentary Act." Indian Folklife 1 (5). http://indianfolklore.org/journals/index.php/IFL/article/view/671.

McDowell, John H. 1979. Children's Riddling. Bloomington: Indiana University Press.

-----. 1999. “The Transmission of Children's Folklore.” In Children's Folklore: A Source Book, edited by Brian Sutton-Smith, Jay Mechling, Thomas W. Johnson, and Felicia 
R. McMahon, 49-62. Logan, Utah: Utah State University Press.

https://doi.org/10.2307/j.ctt46nskz.9.

-----. 2007. "Naming Games and Beyond: Referencing in Children's Verbal Play."

Children's Folklore Review 30: 35-46.

Ratner, Nancy, and Jerome Bruner. 1978. "Games, Social Exchange, and the Acquisition of Language." Journal of Child Language 5: 391-401.

Schramm, Katharine R. M. 2011. "Nascent Folklore: Communication and Aesthetics in Infancy." Children's Folklore Review 33: 7-26.

\footnotetext{
${ }^{1}$ I use the term "peekaboo play" rather than "game," as we did in the book, because "play" is more inclusive and avoids implying that peekaboo necessarily involves an "element of competition, or the possibility of winning or losing" (Brunvand 1998, 479).

${ }^{2}$ Establishing eye contact is step (a) in the peekaboo morphology (Barker and Rice, 181). Often a severing of eye contact happens unexpectedly, and the Agent will seize the opportunity to begin a round of peekaboo built around whatever it was that happened to break eye contact. In forms of peekaboo which focus on hiding and revealing a toy or other figure, eye contact functions differently.
} 